\title{
PENERAPAN YELLOW BOX JUNCTION PADA PERLINTASAN SEBIDANG UNTUK MENGURAI ANTRIAN KENDARAAN AKIBAT PENUTUPAN PINTU PERLINTASAN SEBIDANG
}

\author{
I Dewa Gede Tantara Tesa Putra \\ Taruna DIV Manajemen Keselamatan \\ Transportasi Jalan \\ Politeknik Keselamatan Transportasi \\ Jalan Jalan Semeru No. 3, Slerok, Tegal \\ Timur, Kota Tegal, Jawa Tengah 52125 \\ tessa hyuga@yahoo.co.id
}

\author{
Edi Purwanto \\ Dosen DIV Manajemen Keselamatan \\ Transportasi Jalan \\ Politeknik Keselamatan Transportasi \\ Jalan Jalan Semeru No. 3, Slerok, Tegal \\ Timur, Kota Tegal, Jawa Tengah 52125 \\ edipur68@gmail.com
}

\begin{abstract}
Good transportation is smooth, safe, safe, convenient and efficient transportation. In order to realize such good transportation, effort is needed in overcoming various transportation problems that exist today and then do various further development. One of the transportation problems is the location of the intersection of Jalan Teuku Umar by crossing a plot of KS Tubun Road between the road and the railroad track. The crossing of this plot resulted in congestion in the aftermath of the closure of the railway crossing. This is very dangerous and causes a burden of loss if there is a train that passes at close intervals due to the unraveling of congestion that occurred on Jalan Teuku Umar. The method in this research is research and development. In this research, the research location is Teuku Umar Street. The data collection is divided into primary data and secondary data. Primary data were obtained by directly conducting a survey to a research site on Jalan Teuku Umar. The observation period in the field is done on Sunday, 17 September 2017 for 14 hours from 06.00 to 20.00 WIB. Secondary data is data sourced from institutions - insatansi related to research that is PT. Kereta Api Indonesia on the schedule of passenger trains and freight passing through a plane of Teuku Umar Street. Based on the analysis of the application of yellow box junction at the intersection can decompose the queue length that occurs on Teuku Umar Street.
\end{abstract}

Keywords: Yellow Box Junction, Queue Length, Field crossing

\begin{abstract}
Abstrak
Transportasi yang baik adalah transportasi yang lancar, aman, selamat, nyaman dan efisien. Demi mewujudkan transportasi yang baik tersebut, diperlukan usaha dalam menanggulangi berbagai permasalahan transportasi yang ada saat ini dan kemudian melakukan berbagai pengembangan selanjutnya. Salah satu permasalahan transportasi adalah letak persimpangan Jalan Teuku Umar dengan perlintasan sebidang Jalan KS Tubun antara jalan dengan jalan rel kereta api. Perlintasan sebidang ini mengakibatkan kemacetan pada persinmpangan setelah penutupan perlintasan kereta api. Hal ini sangat berbahaya dan menimbulkan beban kerugian jika terdapat kereta yang melintas dengan interval yang berdekatan karena belum terurainya kemacetan yang terjadi pada Jalan Teuku Umar. Metode dalam penelitian ini adalah research and development. Pada penelitian ini yang menjadi lokasi penelitian adalah Jalan Teuku Umar. Adapun dalam pengumpulan data dibagi atas data primer dan data sekunder. Data primer didapat dengan langsung melakukan survei ke lokasi penelitian di Jalan Teuku Umar. Periode pengamatan di lapangan dilakukan pada hari Minggu, 17 September 2017 selama 14 jam yaitu dari pukul 06.00 sampai 20.00 WIB. Data sekunder adalah data yang bersumber dari instansi - insatansi yang berkaitan dengan penelitian yaitu PT. Kereta Api Indonesia mengenai jadwal kereta api penumpang dan barang yang melewati perlintasaan sebidang Jalan Teuku Umar. Berdasarkan analisis penerapan yellow box junction pada simpang dapat mengurai panjang antrian yang terjadi pada Jalan Teuku Umar.
\end{abstract}

Kata Kunci : Yellow Box Junction, Panjang Antrian, Perlintasan Sebidang 


\section{PENDAHULUAN}

Transportasi yang baik adalah transportasi yang lancar, aman, selamat, nyaman dan efisien. Demi mewujudkan transportasi yang baik tersebut, diperlukan usaha dalam menanggulangi berbagai permasalahan transportasi yang ada saat ini dan kemudian melakukan berbagai pengembangan selanjutnya. Salah satu permasalahan transportasi adalah letak persimpangan dengan perlintasan sebidang antara jalan dengan jalan rel kereta api. Di Indonesia, pertemuan antara dua jenis prasarana transportasi ini telah dioperasikan secara semi otomatis dengan menggunakan palang pintu perlintasan. Walaupun telah dioperasikan dengan semi otomatis, perlintasan sebidang ini sangat berpengaruh terhadap lalu lintas di jalan raya karena sesuai dengan Undang-Undang No.23 Tahun 2007 pasal 124 tentang Perkeretaapian dan Undang-Undang No.22 Tahun 2009 pasal 114 tentang Lalu Lintas dan Angkutan Jalan, pamakai jalan wajib mendahulukan perjalanan kereta api.

Salah satu perlintasan sebidang di Kota Tegal adalah perlintasan sebidang di Jalan Ks Tubun-Tirus-Teuku Umar. Pada perlintasan tersebut juga terdapat persimpangan yang letaknya berdekatan. Kondisi geometrik jalan yang tidak sesuai dengan Peraturan Direktur Jenderal Perhubungan Darat No : SK770/KA.401/DRDJ/2005 Ruas jalan yang dapat dibuat perlintasan sebidang antara jalan dengan jalur kereta api tidak pada tikungan jalan dan/atau alinement horizontal yang memiliki radius sekurang-kurangnya 500 meter mengakibatkan penumpukan antrian kendaraan yang berada pada Jalan Teuku Umar. Perlintasan ini juga merupakan jalur utama kereta api dan kereta barang dari arah Tegal menuju Jakarta maupun sebaliknya dengan frekuensi tinggi. Panjang antrian yang diakibatkan ketika palang pintu perlintasan ditutup mencapai 130 meter dengan lama penutupan mencapai 179 detik.

Perlintasan sebidang ini mengakibatkan kemacetan pada persinmpangan setelah penutupan perlintasan kereta api. Hal ini sangat berbahaya dan menimbulkan beban kerugian jika terdapat kereta yang melintas dengan interval yang berdekatan karena belum terurainya kemacetan yang terjadi pada Jalan Teuku Umar (Pengamatan Survei Pendahuluan, 2017). Dan menurut Sedangkan pada perlintasan sebidang kereta api di jalan KS Tubun-Tirus Kota Tegal ini hanya langsung bertemu antara mulut simpang dan perlintasan sebidang. Hal ini Berdasarkan uraian latar belakang di atas, maka tujuan dari penelitian ini yaitu mengetahui geometrik eksisting jalan pada lokasi studi, untuk mengetahui panjang antrian kendaraan akibat penutupan pintu perlintasan pada Jalan Teuku Umar serta menerapkan yellow box junction untuk mengurai antrian kendaraan akibat penutupan pintu perlintasan sebidang pada Jalan Teuku Umar. 


\section{METODOLOGI PENELITIAN}

Alur penelitian ini dapat dilihat dalam bagan alir pada Gambar 1 dibawah ini :

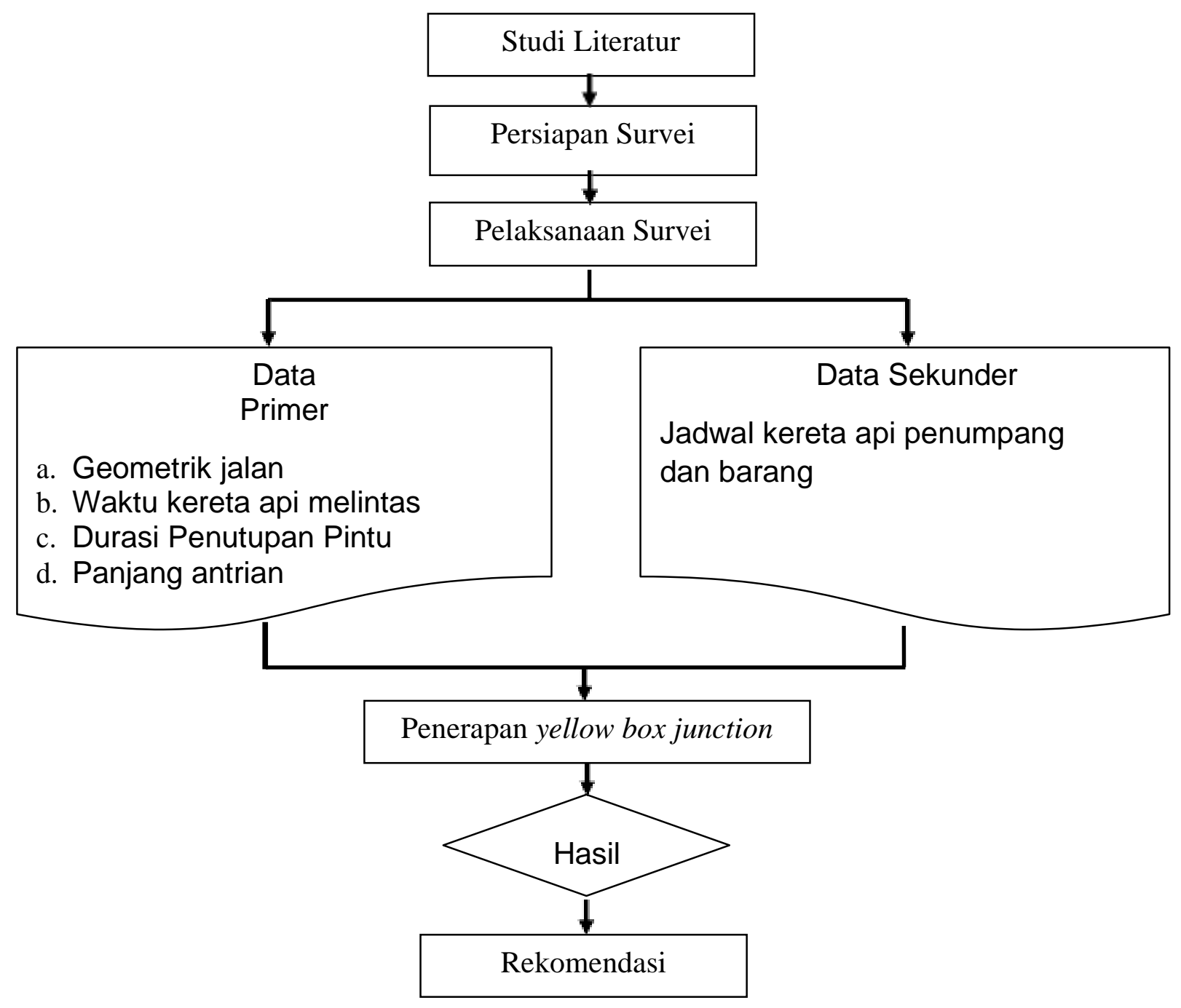

Gambar 1. Bagan Alir Penelitian

Pada penelitian ini yang menjadi lokasi penelitian adalah Jalan Teuku Umar. Penelitian ini menggunakan metode research and development. Pada lokasi tersebut terdapat perlintasan sebidang jalan raya dengan jalur kereta api. Adapun dalam pengumpulan data dibagi atas data primer dan data sekunder.

Data primer didapat dengan langsung melakukan survei ke lokasi penelitian di Jalan Teuku Umar. Periode pengamatan di lapangan dilakukan pada hari Minggu, 17 September 2017 selama 14 jam yaitu dari pukul 06.00 sampai 20.00 WIB.

Data sekunder adalah data yang bersumber dari instansi - insatansi yang berkaitan dengan penelitian yaitu PT.Kereta Api Indonesia mengenai jadwal kereta api penumpang dan barang yang melewati perlintasaan sebidang Jalan Teuku Umar. 


\section{PEMBAHASAN}

\section{Geometrik Jalan}

Lokasi penelitian yang terletak di simpang Jalan Teuku Umar Kota Tegal merupakan jalan provinsi yang berpotongan dengan perlintasan kereta api. Berikut merupakan data geometrik jalan pada perlintasan sebidang Jalan Teuku Umar, dapat dilihat pada Tabel 1.

Tabel 1. Data Geometri Simpang

\begin{tabular}{|c|c|c|c|c|}
\hline No & Nama Ruas Jalan & Lebar & Bahu & Trotoar \\
\hline 1 & Jl. Teuku Umar (dari arah Slawi) & 8 meter & 1 meter & $\begin{array}{l}\text { Tidak } \\
\text { Ada }\end{array}$ \\
\hline 2 & Jl. KS Tubun (dari arah Kota Tegal) & $\begin{array}{c}12 \\
\text { meter }\end{array}$ & 1 meter & $\begin{array}{c}\text { Tidak } \\
\text { Ada }\end{array}$ \\
\hline 3 & Jl. Tirus (dari arah Pantura) & $\begin{array}{c}12 \\
\text { meter }\end{array}$ & $\begin{array}{c}1,5 \\
\text { meter }\end{array}$ & $\begin{array}{l}\text { Tidak } \\
\text { Ada }\end{array}$ \\
\hline
\end{tabular}

(Sumber: Data Survei, 2017)

Kondisi eksisting geometrik jalan dapat diperjelas pada Gambar 2 sebagai berikut.

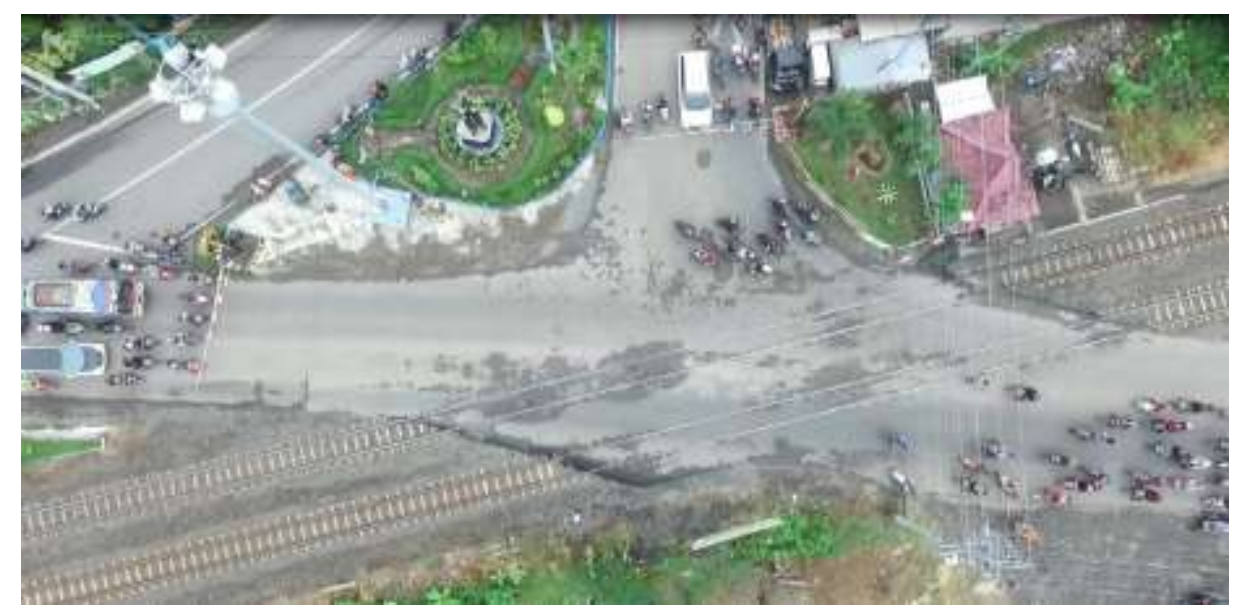

(Sumber: Data Survei, 2017)

Gambar 2. Kondisi eksisting Simpang dan perlintasan

Panjang Antrian berdasarkan Jumlah Kereta yang Melintas dan Waktu Lamanya Penutupan Palang Pintu

Perlintasan sebidang Jalan Teuku Umar ini merupakan perlintasan dengan rel ganda (double track) dengan lebar perlintasan 10 meter. Panjang antrian eksisting berdasarkan jumlah kereta yang melintas dan waktu penutupan palang pintu dapat dilihat pada Tabel 2 dibawah ini. 
Tabel 2. Panjang Antrian Eksisting

\begin{tabular}{|c|c|c|c|c|c|c|}
\hline \multirow[b]{2}{*}{ No } & \multirow[b]{2}{*}{$\begin{array}{l}\text { Nomor } \\
\text { KA }\end{array}$} & \multirow[b]{2}{*}{ Nama KA } & \multirow[b]{2}{*}{$\begin{array}{c}\text { Jadwal } \\
\text { KA }\end{array}$} & \multirow{2}{*}{$\begin{array}{c}\text { Lama } \\
\text { penutupa } \\
\mathrm{n} \text { pintu (s) }\end{array}$} & \multicolumn{2}{|c|}{ Panjang Antrian (m) } \\
\hline & & & & & $\begin{array}{c}\text { Jalur JL.KS } \\
\text { Tubun dan } \\
\text { Jl.Tirus }\end{array}$ & $\begin{array}{c}\text { Jalur ال. } \\
\text { Teuku } \\
\text { Umar }\end{array}$ \\
\hline 1 & 61 & Tegal Bahari & 05.55 & 297 & 65 & 79 \\
\hline 2 & 141 & Majapahit & 06.18 & 253 & 80 & 90 \\
\hline 3 & $2533 F$ & Petikemas & 06.34 & 168 & 60 & 83 \\
\hline 4 & 2505 & Petikemas & 07.19 & 278 & 83 & 112 \\
\hline 5 & 2509 & Petikemas & 07.41 & 179 & 144 & 130 \\
\hline 6 & 11 & Argo Sindoro & 08.14 & 290 & 94 & 126 \\
\hline 7 & 2503 & Petikemas & 08.50 & 263 & 78 & 89 \\
\hline 8 & 401 & Kaligung & 09.03 & 250 & 70 & 79 \\
\hline 9 & 2507 & Petikemas & 09.54 & 276 & 65 & 71 \\
\hline 10 & 149 & Menoreh & 10.38 & 298 & 78 & 84 \\
\hline 11 & 2513 & Petikemas & 10.55 & 277 & 60 & 73 \\
\hline 12 & 407 & Kaligung & 11.28 & 256 & 79 & 84 \\
\hline 13 & 2721 & Semen & 12.02 & 245 & 84 & 86 \\
\hline 14 & 1 & AB. Anggrek & 13.32 & 257 & 89 & 108 \\
\hline 15 & 209 & Tegal Expres & 14.04 & 287 & 94 & 126 \\
\hline 16 & 2511 & Petikemas & 14.34 & 245 & 60 & 79 \\
\hline 17 & 63 & Tegal Bahari & 15.04 & 148 & 80 & 83 \\
\hline 18 & 201 & Tawang Jaya & 15.59 & 278 & 100 & 94 \\
\hline 19 & 2517 & Petikemas & 16.24 & 260 & 78 & 90 \\
\hline 20 & 65 & Tegal Bahari & 17.16 & 185 & 67 & 82 \\
\hline 21 & $2539 F$ & Petikemas & 17.29 & 260 & 74 & 80 \\
\hline 22 & 2713 & Semen & 17.49 & 240 & 70 & 96 \\
\hline 23 & 13 & Argo Muria & 18.15 & 250 & 80 & 73 \\
\hline 24 & 2709 & Semen & 18.40 & 197 & 75 & 83 \\
\hline 25 & 2703 & Semen & 19.04 & 280 & 72 & 75 \\
\hline 26 & 97 & Ciremai & 20.07 & 277 & 60 & 73 \\
\hline
\end{tabular}

(Sumber: Data Survei, 2017)

Panjang antrian terpanjang pada perlintasan sebidang adalah 130 meter pada Jalan Teuku Umar. Hal ini sudah melebihi jarak eksisting antara persimpangan dengan perlintasan kereta dan menimbulkan penumpukan pada persimpangan jika terdapat kereta api yang melintas. 


\section{Penerapan Yellow Box Junction}

Berdasarkan hasil analisis yaitu panjang antrian terpanjang pada perlintasan sebidang adalah 130 meter pada Jalan Teuku Umar pukul 07.40 WIB (jam sibuk). Oleh karena itu, peneliti akan menerapkan yellow box junction untuk mengurai antrian panjang yang ada pada Jalan Teuku Umar. Berikut merupakan desain yellow box junction pada simpang dapat dilihat pada Gambar 3.

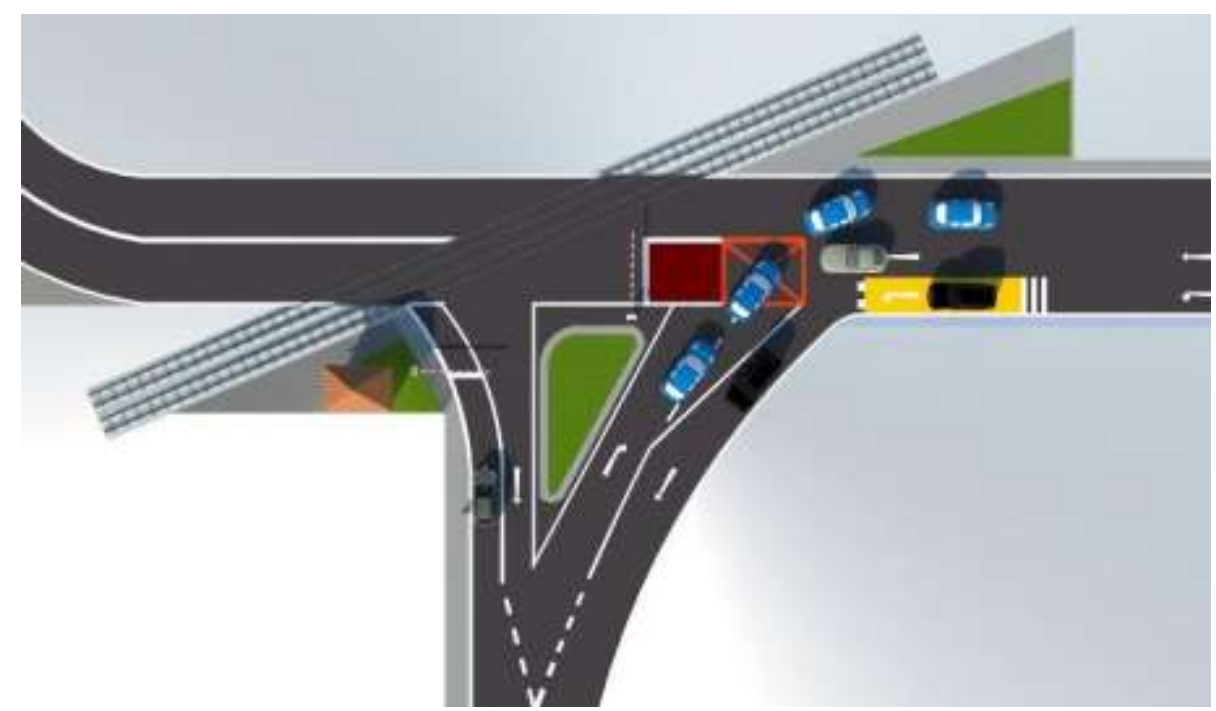

(Sumber: Analisis Data, 2017)

Gambar 3. Yellow Box Junction Design

Hasil penerapan yellow box junction pada simpang dapat dilihat pada Tabel 3 berikut.

Tabel 3. Penerapan Yellow Box Junction

\begin{tabular}{|c|c|c|c|c|c|c|}
\hline \multirow[b]{2}{*}{ No } & \multirow[b]{2}{*}{$\begin{array}{c}\text { Nomor } \\
\text { KA }\end{array}$} & \multirow[b]{2}{*}{ Nama KA } & \multirow[b]{2}{*}{$\begin{array}{c}\text { Jadwal } \\
\text { KA }\end{array}$} & \multirow{2}{*}{$\begin{array}{l}\text { Lama } \\
\text { penutupan } \\
\text { pintu (s) }\end{array}$} & \multicolumn{2}{|c|}{ Panjang Antrian (m) } \\
\hline & & & & & $\begin{array}{c}\text { Jalur JL.KS } \\
\text { Tubun dan } \\
\text { Jl.Tirus }\end{array}$ & $\begin{array}{c}\text { Jalur Jl. } \\
\text { Teuku } \\
\text { Umar }\end{array}$ \\
\hline 1 & 61 & Tegal Bahari & 05.55 & 297 & 85 & 0 \\
\hline 2 & 141 & Majapahit & 06.18 & 253 & 74 & 0 \\
\hline 3 & $2533 \mathrm{~F}$ & Petikemas & 06.34 & 168 & 82 & 0 \\
\hline 4 & 2505 & Petikemas & 07.19 & 278 & 93 & 0 \\
\hline 5 & 2509 & Petikemas & 07.41 & 179 & 149 & 0 \\
\hline 6 & 11 & Argo Sindoro & 08.14 & 290 & 98 & 0 \\
\hline 7 & 2503 & Petikemas & 08.50 & 263 & 86 & 0 \\
\hline 8 & 401 & Kaligung & 09.03 & 250 & 70 & 0 \\
\hline 9 & 2507 & Petikemas & 09.54 & 276 & 67 & 0 \\
\hline 10 & 149 & Menoreh & 10.38 & 298 & 81 & 0 \\
\hline 11 & 2513 & Petikemas & 10.55 & 277 & 69 & 0 \\
\hline
\end{tabular}




\begin{tabular}{|c|c|c|c|c|c|c|}
\hline 12 & 407 & Kaligung & 11.28 & 256 & 74 & 0 \\
\hline 13 & 2721 & Semen & 12.02 & 245 & 88 & 0 \\
\hline 14 & 1 & $\begin{array}{c}\text { AB. } \\
\text { Anggrek }\end{array}$ & 13.32 & 257 & 82 & 0 \\
\hline 15 & 209 & $\begin{array}{l}\text { Tegal } \\
\text { Expres }\end{array}$ & 14.04 & 287 & 99 & 0 \\
\hline 16 & 2511 & Petikemas & 14.34 & 245 & 65 & 0 \\
\hline 17 & 63 & $\begin{array}{c}\text { Tegal } \\
\text { Bahari }\end{array}$ & 15.04 & 148 & 87 & 0 \\
\hline 18 & 201 & $\begin{array}{c}\text { Tawang } \\
\text { Jaya }\end{array}$ & 15.59 & 278 & 112 & 0 \\
\hline 19 & 2517 & Petikemas & 16.24 & 260 & 76 & 0 \\
\hline 20 & 65 & $\begin{array}{l}\text { Tegal } \\
\text { Bahari }\end{array}$ & 17.16 & 185 & 90 & 0 \\
\hline 21 & $\begin{array}{c}2539 \\
F\end{array}$ & Petikemas & 17.29 & 260 & 83 & 0 \\
\hline 22 & 2713 & Semen & 17.49 & 240 & 74 & 0 \\
\hline 23 & 13 & Argo Muria & 18.15 & 250 & 87 & 0 \\
\hline 24 & 2709 & Semen & 18.40 & 197 & 67 & 0 \\
\hline 25 & 2703 & Semen & 19.04 & 280 & 96 & 0 \\
\hline 26 & 97 & Ciremai & 20.07 & 277 & 78 & 0 \\
\hline
\end{tabular}

Berikut merupakan penerapan yellow box junction, dapat dilihat pada Gambar 4.

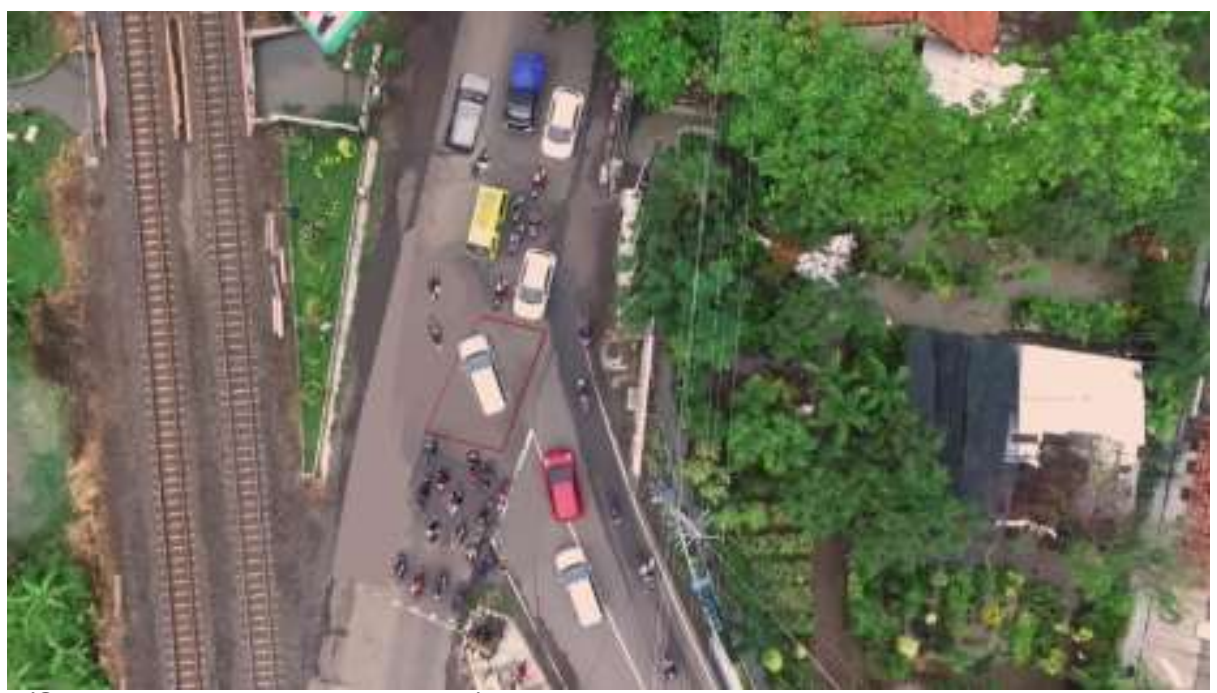

(Sumber: Analisis Data, 2017)

Gambar 4. Penerapan Yellow Box Junction

Dapat dilihat pada gambar diatas bahwa penerapan yellow box junction pada simpang dapat mengurai panjang antrian yang terjadi pada Jalan Teuku Umar. 


\section{PENUTUP}

Berdasarkan hasil pembahasan, dapat ditarik kesimpulan bahwa Jalan Teuku Umar memiliki lebar jalan 8 meter, Jalan KS Tubun 12 meter dan Jalan Tirus 12 meter. Panjang antrian terpanjang pada perlintasan sebidang adalah 130 meter pada Jalan Teuku Umar pukul 07.40 WIB (jam sibuk) dengan durasi penutupan palang pintu perlintasan sebidang mencapai 179 detik. Berdasarkan analisis penerapan yellow box junction pada simpang dapat mengurai panjang antrian yang terjadi pada Jalan Teuku Umar.

\section{DAFTAR PUSTAKA}

Amal, A.S., dkk. (2002). "Pengaruh Penutupan Pintu Kereta Api Terhadap Tundaan dan Panjang Antrian Kendaraan Pada Jalan Raya MalangSurabaya Km.10. Malang". Jurnal Pilar, volume 11 nomor 2

Departemen Pekerjaan Umum (DPU) Direktorat Binamarga. (1997). Manual Kapasitas Jalan Indonesia (MKJI).

Direktorat Jenderal Perhubungan Darat.2005. SK 770/KA.401/DRJD/2005/Dirjen Hubdar, Pedoman Teknis Perlintasan Sebidang Antara Jalan dan Jalur Kereta Api.

Julianto, Eko Nugroho. (2010). "Hubungan Antara Kecepatan, Volume dan Kepadatan Lalu Lintas Ruas Jalan Siliwangi Semarang”. Jurnal Teknik Sipil dan Perencanaan, Volume 12 no.2

Kementerian Perhubungan.2000. Keputusan Menteri Perhubungan No. KM 35 Tahun 2000 Tentang Perpotongan dan/atau Persinggungan Antara Jalur Kereta Api Dengan Bangunan Lain.

May, A.D.(1990).Traffic Flow Fundamental. Prentice-Hall Inc, New Jersey

Mulyono, Gatot Slamet. (2006). "Analisis Lalu Lintas Pertemuan Jalan Raya Dengan Lintasan Kereta Api Ledok Sari di Surakarta". Jurnal Eco Rekayasa, volume 2 no. 1

Putranto, L. S. 2008. Rekayasa Lalu Lintas.Jakarta : Penerbit Indeks.

Rahman, Rahmatang. (2010). "Analisa Kelayakan Pembangunan Flyover di Bundaran Dolog Kota Surabaya”. Jurnal Majalah IImiah Mektek Tahun XII no.1

Said. (2004). Kajian Satu Persimpangan Sebidang Jalan Dan Jalan Rel.Tesis ITB, Bandung Sari, Ika Endah. 2003. Perhitungan Biaya Tundaan Lalu Lintas Di Jalan Balai Kota Medan-

Kota Medan. Medan : Tesis Program Pasca Sarjana Universitas

Sumatera Utara. Setiyaningsih, Ika. 2007. Karakteristik Lalu Lintas Pada

Persilangan Sebidang Jalan dan Jalan Rel. Bandung :Tesis ITB.

Soedirdjo, T.L. (2002).Rekayasa Lalu Lintas. Penerbit ITB, Bandung

Suratmaja, I.P.dkk. "Analisa Biaya Perjalanan Akibat Tundaan Lalu Lintas (Studi kasus : Ruas Jalan Dari Persimpangan JI. I Gusti Ngurah Rai - Jl. Siligita Sampai Persimpangan Jl. I Gusti Ngurah Rai - JI.Gopala". Jurnal ilmiah elektronik Infrastruktur Teknik Sipil, Denpasar

Tamin, O.Z. 2000. Perencanaan dan Pemodelan Transportasi. Bandung : Penerbit Institut Teknologi Bandung.

Warpani, Suwardjoko. (1993). Rekayasa Lalu Lintas. Penerbit Bharatara, Jakarta. 